\title{
F. Lestringant, "Je suis moi-même la matière de mon livre». Lecture du livre III des "Essais"
}

\section{Sabine Lardon}

\section{(2) OpenEdition}

1 Journals

\section{Édition électronique}

URL : http://journals.openedition.org/studifrancesi/10551

DOI : 10.4000/studifrancesi. 10551

ISSN : 2421-5856

Éditeur

Rosenberg \& Sellier

\section{Édition imprimée}

Date de publication : 1 décembre 2017

Pagination : 543

ISSN : 0039-2944

\section{Référence électronique}

Sabine Lardon, «F. Lestringant, "Je suis moi-même la matière de mon livre». Lecture du livre III des

"Essais" », Studi Francesi [En ligne], 183 (LXI | III) | 2017, mis en ligne le 01 février 2018, consulté le 21 janvier 2021. URL : http://journals.openedition.org/studifrancesi/10551 ; DOI : https://doi.org/ 10.4000/studifrancesi.10551

Ce document a été généré automatiquement le 21 janvier 2021.

\section{(c) 9 (i) $\Theta$}

Studi Francesi è distribuita con Licenza Creative Commons Attribuzione - Non commerciale - Non opere derivate 4.0 Internazionale. 


\title{
F. Lestringant, "Je suis moi-même la matière de mon livre». Lecture du livre III des "Essais"
}

\author{
Sabine Lardon
}

\section{RÉFÉRENCE}

FRANK LESTRINGANT, «Je suis moi-même la matière de mon livre». Lecture du livre III des

"Essais", Rouen, Presses universitaires de Rouen et du Havre - CNED, 2016, 212 pp.

1 Fruit d'une collaboration entre les PURH et le CNED, cette collection s'adresse aux étudiants, et plus particulièrement aux agrégatifs. Cet ouvrage répond donc aux attentes de la collection, en proposant une introduction claire et méthodique au livre III des Essais de Montaigne, au programme de l'agrégation 2017 de Lettres. La section I, «Michel de Montaigne (1533-1592)», présente d'abord une synthèse biographique (naissance et éducation de Michel de Montaigne, l'amitié avec La Boétie, la «retraite», le voyage en Italie, la mairie de Bordeaux, la fin de vie). La section II, «Les Essais», dégage ensuite les enjeux du titre innovant et polysémique, avant de s'intéresser à la forme singulière de l'essai, qui tient du florilège et du commentaire, puis au rapport des chapitres avec leurs titres «qui n'en embrassent pas toujours la matière» ainsi que le rappelle Montaigne lui-même (III, 9). La section III, «La bibliothèque des Essais», envisage la question des sources, la pensée de Montaigne, l'omniprésence du contexte des guerres de religion, la conception de l'homme et l'importance du corps, le rapport entre les Essais et le temps de l'éphéméride mis en lumière par Bruno Méniel, la persona de l'auteur, et enfin le style d'une pensée en mouvement. La section IV enfin, «Cheminements de chapitres», considère successivement de nombreux chapitres du livre (III, 2, 5, 6, 8, 9, 11, 12, 13 ainsi qu'une étude d'un extrait du chapitre 13) en élucidant le sens du chapitre et sa place dans l'œuvre. L'ouvrage est complété par une bibliographie, qui signale les ouvrages indispensables par un astérisque, ainsi que par une anthologie commentée de la réception de Montaigne à travers les siècles. Par-delà 
son objectif immédiat dans le cadre du programme d'agrégation 2017, cet ouvrage d'introduction au livre III des Essais de Montaigne pourra être également recommandé pour les étudiants de licence ou de master abordant ce texte dans le cadre d'un cours, d'un séminaire ou d'un travail de recherche. 